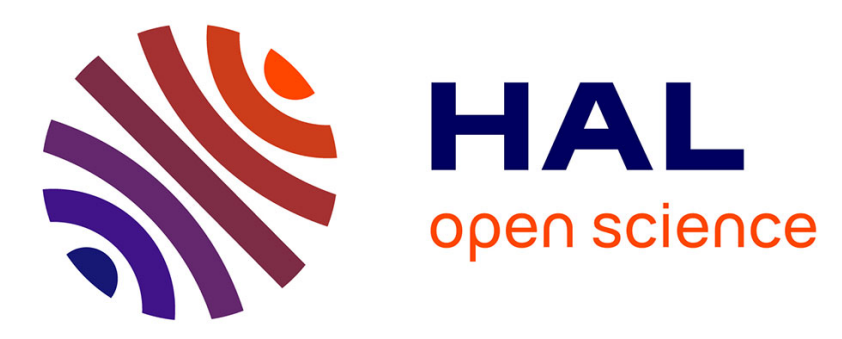

\title{
The influence of unintended field retting on the physicochemical and mechanical properties of industrial hemp bast fibres
}

\author{
Vincent Placet, Arnaud Day, Johnny Beaugrand
}

\section{To cite this version:}

Vincent Placet, Arnaud Day, Johnny Beaugrand. The influence of unintended field retting on the physicochemical and mechanical properties of industrial hemp bast fibres. Journal of Materials Science, 2017, 52 (10), pp.5759-5777. 10.1007/s10853-017-0811-5 . hal-01607015

\section{HAL Id: hal-01607015 https://hal.science/hal-01607015}

Submitted on 26 May 2020

HAL is a multi-disciplinary open access archive for the deposit and dissemination of scientific research documents, whether they are published or not. The documents may come from teaching and research institutions in France or abroad, or from public or private research centers.
L'archive ouverte pluridisciplinaire HAL, est destinée au dépôt et à la diffusion de documents scientifiques de niveau recherche, publiés ou non, émanant des établissements d'enseignement et de recherche français ou étrangers, des laboratoires publics ou privés.

$$
\text { Copyright }
$$




\title{
The influence of unintended field retting on the physicochemical and mechanical properties of industrial hemp bast fibres
}

\author{
Vincent Placet ${ }^{1, \star}$ (D), Arnaud Day ${ }^{2,3}$, and Johnny Beaugrand ${ }^{4}$ \\ ${ }^{1}$ Université Bourgogne Franche-Comté, FEMTO-ST Institute, CNRS/UFC/ENSMM/UTBM, 25000 Besançon, France \\ ${ }^{2}$ Fibres Recherche Développement, Technopole de l'Aube en Champagne, Hôtel de Bureaux 2 - 2 rue Gustave Eiffel, \\ CS 90601 - 10901 Troyes Cedex 9, France \\ ${ }^{3}$ CNRS, UMR8576, UGSF- Unité de Glycobiologie Structurale et Fonctionnelle, Unité de Lille, 59000 Lille, France \\ ${ }^{4}$ INRA, Université de Reims Champagne-Ardenne, 51100 Reims, France
}

Received: 18 November 2016

Accepted: 16 January 2017

(C) Springer Science+Business Media New York 2017

\begin{abstract}
Developing hemp fibre composites for structural applications requires both reconsideration and optimisation of the transformation processes to obtain stable, high-quality fibre reinforcements. In this context, field retting remains an important issue because it is weather dependent and has not been completely mastered by the hemp industries. Retting can be achieved voluntarily to facilitate fibre separation and extraction from the stalks prior to mechanical decortication. However, retting can also be involuntary and result from climatic misfortune and unforeseeable events at the time of harvest. Therefore, this study aimed to quantify the influence of involuntary and non-controlled field retting on the physicochemical and mechanical properties of industrial hemp bast fibres. A wide spectrum of analytical techniques was applied, including colour spectrophotometry; morphological, microscopic (SEM), surface (EDX, roughness), biochemical (HPLC and pXRD) and thermogravimetric (TGA) analyses; dynamic vapour sorption; and tensile characterisation. The results indicate that retting induced a decrease in the average width of fibre elements after mechanical processing and a loss of pectic substances. We also observed a change in colour from yellow to dark grey, an increase in surface roughness and an increase in the decomposition temperature for the third mass loss region. A decrease in tensile properties at the scales of both single and technical fibres was also observed. Since no significant decrease in cellulose content was measured, this decay in mechanical performance was connected with both the significant degradation of hemicelluloses and a decrease in the fraction of crystalline cellulose that was quantified in this work.
\end{abstract}

Address correspondence to E-mail: vincent.placet@univ-fcomte.fr 


\section{Abbreviations}

NR-SF Non-retted single fibres

NR-TF Non-retted technical fibres

R-SF Retted single fibres

R-TF Retted technical fibres

SF $\quad$ Single fibres

TF Technical fibres

\section{Introduction}

Industrial hemp has gained momentum in recent years. The increasing demand for fibres has led to a new record acreage cultivation area of 22,000 ha in Europe [1]. Since the rediscovery of industrial hemp at the end of the twentieth century, new opportunities have emerged for its fibres in addition to the traditional applications in the pulp and paper industries.

Today, the primary applications for hemp bast fibres are still in the fields of pulp and paper (55\%), insulation materials and non-woven products $(26 \%)$ and polymer composites (15\%) [2]. The only very well-established hemp fibre-reinforced polymer (HFRP) market is that of press and injection moulding for automotive interior applications [2]. For these types of products, hemp fibres are employed primarily as light, inexpensive and eco-friendly reinforcements [3, 4]. Considering their high mechanical performance [4-13], the use of hemp fibres as substitutes for traditional composite reinforcements, particularly E-glass, in load-bearing materials appears to be an achievable challenge for the hemp industry.

The literature reports that the load-bearing capacity of plant fibre composites (PFC) is governed by the separation level, quantity, alignment and dispersion properties of the fibres and the adhesion between the fibres and matrix [14-17]. Optimising the hemp fibre transformation processes up to the composite scale is necessary to obtain high-performance composites and could require a reconsideration of the extraction and fibre separation processes that are traditionally used in the hemp industry. The actual processes, primarily tailored for paper applications, do not have the same objectives that composite applications have in terms of fibre properties. For high-scale production with a long-life production cycle, such as transport industries, a disruption of the supply chain and/or a non-conformity of feedstocks is not allowed. In this industrial context, hemp fibres employed as reinforcement in composites should be well qualified to ensure the constant quality of the final product. However, hemp straw is produced in a large area with different soils and/or climates and various agricultural practices, which could generate a strong heterogeneity of straw and fibre qualities. Among the parameters that can alter straw and fibre quality, one appears to be of primary importance: the retting level of straw.

Retting is a biological process that can remove the pectic substances that bond the bast fibres both to each other and to the other constituents of the stalk [18]. After being cut at their base, hemp stems are laid on the ground for a period ranging from a few days to several weeks, according to the expected level of retting, the weather and the possibility for farmers to harvest straw in good condition to ensure their stock. The presence of either dew or liquid water and a mean temperature of approximately $15{ }^{\circ} \mathrm{C}$ provides the conditions for the development of microorganisms (fungi and bacteria), whose enzymatic activities can degrade the components of the middle lamella and of the cell wall [19]. Consequently, the results of retting are highly influenced by geographic region, water quality and weather conditions, parameters that directly affect both the proliferation of microorganisms and the intensity of their enzymatic activity [20].

Therefore, in Europe, the methods used by processing companies for separating hemp bast fibres bypass traditional field retting. In this case, the baling process (after mowing and windrowing stalks) is conducted as soon as possible to prevent straw retting to the greatest extent possible. However, if weather vagaries occur (as illustrated by climatic misfortunes that occur from time to time, as in 2013 in France, when the weather conditions did not allow for baling in time), the stalks undergo an unwanted and uncontrolled retting. The latter situation appears unacceptable for the emerging markets (non-woven, thermoplastic composites), who must manage this unwanted retted straw, and final users of fibres, who need consistent fibre quality [3].

The influence of retting on fibre quality has been well documented for flax: retting could especially affect chemical composition, tissular cohesion and fibre mechanical properties [21]. Some conclusions could be generalised to other bast fibre-rich plants (hemp, jute, ramie and kenaf), but specific 
characteristics (harvest dates, production area, stem tissular organisation and the presence of secondary fibre) particularly suggest considering retting for each plant [22-25].

For hemp, retting has been mainly investigated at the scale of laboratory batches and incubators and most of the data available are focused on the monitoring of the activity of the effectors (i.e. enzymatic production, microbial development and carbohydrate release) [26-31]. The impact of retting on mechanical properties has mainly been evaluated at the scale of composite materials rather than at the scale of the hemp fibres themselves. The increase in mechanical properties that can be observed at the scale of composites reinforced with short fibres must be interpreted with great care. Saleem et al. [32] showed that this increase was effectively attributed to both the fibre refining and the increase in the resulting aspect ratio (technical fibres were separated into smaller bundles and single fibres), not to an improvement in the mechanical properties of the fibres themselves. In fact, a high decrease in the tensile strength of these fibres was measured (455-171 MPa). When evaluated at the scale of the fibres themselves [22-24, 33], fibres are generally extracted from the stem manually.

Quality management of straw and fibres appears as another major issue that could interfere with the use of hemp fibres in material industries. At the industrial scale, this process is achieved only using a mechanical process in which the stalks are passed through different millers and/or fluted rollers to crush and break the woody core into short pieces (shives, sometimes called 'chenevotte' or woody hemp core) and thus separate the bast fibres. This aggressive process is very different to the manual extraction classically used at a laboratory scale and could lead to variation in the main conclusions established when separating the fibres manually.

Thus, to elucidate the impact of uncontrolled retting on hemp fibre quality in the context of industrial production, we took advantage of an unintended field retting (France, 2013) resulting from a delay in the baling process due to rain to evaluate the influence on the characteristics of the fibre materials. In this case, as it can occur time to time, the straw baling is only conditioned by the feasibility of the baling process (i.e. by the accessibility of agricultural machinery to fields) and not by the quality of the straws, as in the case of a controlled retting. In such a case, a high heterogeneity in the straw quality and in the level of retting (potentially including low-retted and over-retted straws) can be obtained within the straw bales. The main question that is raised by farmers is to know whether they can valorise these straws and the resulting fibres. Indeed, such a situation can be unacceptable for both fibre processors who should manage these unwanted and heterogeneous retted straws and final users of fibres who need fibres with a constant and guaranteed quality. So, the economic and industrial consequences are critical.

The aim of this study was to characterise the influence of unintended field retting on industrial hemp fibres and to compare non-retted and retted fibre qualities. This study focused on the retting consequences across a wide spectrum of both physicochemical and mechanical properties, and it sought to fill a gap in the literature, as the parameters of the retting process and soil/microbial variables are arguably well depicted. In addition to promoting better hemp straw management, these results could help elucidate the effectiveness of retting. It is of paramount importance to establish the relationship between the treatment and the characteristics of the fibre elements, including the morphological, surface, interfacial and mechanical properties of the isolated technical or single fibres.

\section{Materials and methods}

\section{Plant material}

The industrial hemp fibres (Cannabis sativa L., cultivars 'Fedora 17 ') tested in this study were supplied by La Chanvrière, a company in Bar-sur-Aube, France. The technical fibres (TFs) were delivered in a jumbled state after extraction was performed using an industrial mechanical process that includes breaking and scutching of the stalks.

Two types of TF were provided: non-retted technical fibre (NR-TF) and retted technical fibre (R-TF). Both were extracted from straw that was harvested in autumn 2013 in the region of Champagne-Ardenne within a radius of $100 \mathrm{~km}$ around Bar-sur-Aube (48.232184, 4.707022).

For the first batch (NR-TF), straw was harvested before the rainy period: once mown, the straw was windrowed, turned over two times and formed into bales. The baling process was performed as soon as 
possible to prevent straw retting as usually performed by farmer for paper industries. For the second batch (R-TF), stalks were harvested after the rainy period: once mown, the straw was windrowed, turned over one time and laid on the soil because unsatisfactory weather conditions prevented the baling process. After approximately five weeks, the straw was turned over one more time and baled. During these five weeks, a dew retting process, also called field retting, occurred.

The fibre extraction process and machinery used for both batches of straw were the same and provided two TF lots: NR-TF and R-TF

\section{Analytical techniques for fibre characterisation}

\section{Colour spectrophotometry}

The colour of the fibres was measured using a spectrophotometer (BYK Gardner). The reference illuminant was D65 (standard daylight), and the observation angle was $10^{\circ}$, according to the CIE 15.2 publication and ISO 11664 recommendations. Data were reported in the CIE $L^{*} a^{*} b^{*}$ colorimetric system, also called CIELAB elsewhere [33]. Retinal colour stimuli were translated into distinctions between light and dark, red and green, and blue and yellow. The luminance represents lightness, in which the values range from 0 (black) to 100 (white). The chrominance parameter ( $a$ and $b$ ) values range from positive to negative. On the a-axis, positive values indicate the amount of red, whereas negative values indicate the amount of green. On the b-axis, yellow is positive and blue is negative. For each type of fibre ( $\mathrm{R}-\mathrm{TF}$ and NR-TF), three measurements were performed on the upper side of the batch.

\section{Fibre morphology characterisation}

Microscopic examination The raw fibres were first examined using polarised light microscopy (Nikon Eclipse LV 150) and scanning electron microscopy (Leica Cambridge Stereoscan S-440 and Hitachi TM 1000 Tabletop Microscope) using secondary electron imaging. Several images were digitally recorded for each fibre to identify their morphological specificities and to provide representative illustrations.
Morphological analysis The fibre dimensions and morphologies were obtained using the MorFi automated apparatus (Techpap, Grenoble, France), and images were analysed using MorFi software. Because TFs are decimetric, their length cannot be easily measured, especially using the MorFi equipment, because elements longer than approximately $10 \mathrm{~mm}$ cannot be analysed (see [34] for more details). Prior to analysis, $3 \mathrm{~g}$ of both retted and non-retted TFs was manually cut using a razorblade. The target length was $2 \mathrm{~mm}$. The purpose of this step is first to homogenise each sample type, thus making them more representative. Second, this step allows for the optimal use of the MorFi system, allowing the accurate determination of the average diameter of the samples. For this purpose, a precise mass of approximately $0.4 \mathrm{~g}$ of the 2-mm-long cut samples was diluted in water extemporarily. Both the retted and non-retted samples were tested in duplicate; over 4,000 fibre elements were counted for each sample. Only the mean diameter (D) values and distribution are presented; the length (L) and thus the aspect ratio (L/D) are not representative of the characteristics of the fibres in the stem.

\section{Fibre surface characterisation}

Roughness The surface texture of single fibres was characterised using a non-contact profilometer. The Infinite Focus ${ }^{\circledR}$ metrology system was developed by Alicona; it is an optical 3D device that achieves micromeasurements with a vertical resolution of up to $10 \mathrm{~nm}$ on large areas. Areal-based surface roughness measurements were performed according to ISO 25178 on three fibres from each batch. For each fibre, approximately three measurements were obtained from elevated areas of approximately $400 \mu \mathrm{m}^{2}$ of the fibre topography. Typical height amplitude parameters (Sa and Sq) were computed. Sa and Sq are the arithmetical mean height and the root-mean-square height of the surface, respectively. These 3D surface texture parameters were computed on the entire surface by averaging the estimations calculated on a number of base lengths, as was the case for the $2 \mathrm{D}$ parameters.

Energy-dispersive X-ray spectroscopy (EDS) An elemental analysis of the technical and isolated single fibres was performed using a probe for energy-dispersive X-ray spectroscopy and the electron beam 
excitation of the Leica Cambridge Stereoscan S-440 SEM.

\section{Biochemical composition}

Chemical analysis Prior to lignin and carbohydrate content determinations, both retted technical fibres (R-TF) and non-retted technical fibres (NR-TF) were powdered for the purpose of sample homogenisation. For this purpose, $10 \mathrm{~g}$ of each sample type was milled in liquid $\mathrm{N}_{2}$ (to limit any heating effects) in a centrifugal grinding mill (Retsch ZM100) equipped with a $0.5-\mathrm{mm}$ sieve. These samples were further used for biochemical investigations.

The lignin contents were determined using the Klason method. The acid-insoluble residue was determined using the non-hydrolysable acid residue remaining after sulphuric acid hydrolysis [35]. For this purpose, $400 \mathrm{mg}$ of cryo-ground R-TF or NR-TF was suspended in $3.0 \mathrm{ml}$ of $12 \mathrm{M} \mathrm{H}_{2} \mathrm{SO}_{4}$ for $2 \mathrm{~h}$ at room temperature. The preparations were then diluted to $1 \mathrm{M}$ with deionised water, heated to $100{ }^{\circ} \mathrm{C}$ for $3 \mathrm{~h}$ and filtered. The remaining residues were dried at $105{ }^{\circ} \mathrm{C}$, and ash measurements were performed after $4 \mathrm{~h}$ at $500{ }^{\circ} \mathrm{C}$. Klason lignin percentages were calculated using the differences in the mass of the samples before and after the ash measurements. The experiment was performed in triplicate, and the mean values are given.

Carbohydrate identification and quantification were performed using HPAEC (ICS- $5000^{+}$DC, Dionex) following a procedure described elsewhere [36] with slight modifications [37] allowing adaptations to the material composition. Neutral and acidic carbohydrates were determined from approximately $5 \mathrm{mg}$ of cryo-ground samples, which were subjected to hydrolysis in $12 \mathrm{M} \mathrm{H}_{2} \mathrm{SO}_{4}$, filtered and injected into a CarboPac PA-1 anion-exchange column $(4 \times 250$ $\mathrm{mm}$, Dionex). The monosaccharide composition was quantified using 2-deoxy-D-ribose as the internal standard, with standard solutions of neutral carbohydrates (L(-fucose, L-arabinose, D-glucose, D-xylose, D-galactose, and $\mathrm{D}(+)$-mannose) and uronic acids $(\mathrm{D}(+)$-galacturonic acid and $\mathrm{D}(+)$-glucuronic acid). Analyses were performed in three independent assays for both R-TF and NR-TF. The carbohydrate content, which is the sum of the amounts of monosaccharide, is expressed as a percentage of the dry matter mass. Analyses were performed in three independent assays for both R-TF and NR-TF.
Powder X-ray diffraction ( $p X R D$ ) X-ray diffraction analyses were performed on a Bruker D8 Advance diffractometer. The beam was monochromated to obtain $\mathrm{CuK} \alpha_{1}$ radiation (wavelength $\lambda=1.5406 \AA$ ). Data were collected in reflection mode over the $2 \theta$ range of $5^{\circ}$ to $60^{\circ}$, with a step size of $0.02^{\circ}$ and a counting time of $0.7 \mathrm{~s}$ per step.

Raw fibres were cut and sieved to obtain a powder, whose particles were less than $200 \mu \mathrm{m}$ in size.

The sample crystallinity was defined as the ratio of the amount of crystalline cellulose to the total amount of sample material, including crystalline and amorphous components. The cellulose crystallinity was defined as the ratio of crystalline cellulose per $100 \mathrm{~g}$ of cellulose and was calculated as the ratio of the sample crystallinity to the cellulose content of the sample. Among the different empirical methods classically used to determine the crystalline part of a diffraction pattern to determine the sample crystallinity [38], we selected the Rietveld method.

Water sorption isotherms and the determination of water uptake

The isotherms of the water vapour desorption/adsorption were determined using a Dynamic Vapour Sorption (DVS) apparatus from Hiden Isochema Ltd. (UK). Approximately $2-5 \mathrm{mg}$ of R-TF or NR-TF sample was placed into the inox nacelle of the microbalance (accuracy of $0.1 \mu \mathrm{g}$ ) and then placed hermetically into a double-jacket reactor that was connected to a thermostated water bath. Four and three replicates were performed for NR-TF and R-TF, respectively. The reactor was equipped with temperature and relative humidity (RH) sensors to monitor these parameters $\left(T^{\circ}=20^{\circ} \mathrm{C}\right)$. RH was obtained with a flow mixture of wet and dry nitrogen. Additional technical details are available in a previous report [39].

The water uptake $\omega$ of the hemp fibre was recorded at equilibrium for the chosen $\mathrm{RH}$ values and was calculated as follows using the mass $m_{\text {moist }}$ measured at the equilibrium moisture content (EMC):

$\omega(\%)=100 \times \frac{m_{\text {moist }}-m_{\text {dry }}}{m_{\text {dry }}}$

Once the samples were equilibrated at 95\% RH, a stepwise 'drying' set-up was applied by decreasing the $\mathrm{RH}$ to the dried state $(0 \% \mathrm{RH})$. Afterwards, an adsorption cycle was performed. 
Thermogravimetric analysis (TGA)

Thermogravimetric analyses of the fibres were performed on a TGA-TDA/DSC apparatus (SETSYS Evolution-SETARAM Instrumentation). Samples of approximately $20 \mathrm{mg}$ of TFs with sizes of less than $200 \mu \mathrm{m}$ were prepared. At least three samples from each batch were heated in argon at a rate of $2{ }^{\circ} \mathrm{C} \mathrm{min}^{-1}$ from ambient temperature to $600{ }^{\circ} \mathrm{C}$. The mass variation was recorded as a function of heating time. Each sample was analysed separately and overlapped for comparison

\section{Tensile characterisation of the fibres}

Both technical and single fibres (TFs and SFs, respectively) were tensile tested. The SFs were manually extracted from the TFs using tweezers. The single and technical fibres were glued onto thin paper supports using Loctite adhesive (super glue 3) to facilitate their handling prior to testing. Approximately $100 \mathrm{SFs}$ and $30 \mathrm{TFs}$ from each batch were tested.

TFs and isolated SFs were first examined using polarised light microscopy (Nikon Eclipse LV 150) to determine their external width. The average width of each fibre was computed by obtaining ten measurements along its length.

A dynamic mechanical analyser (DMA Bose Electroforce 3230) was used to perform tensile static tests. The paper frame supporting each fibre was clamped onto the testing machine. Thereafter, the fibre was conditioned inside of the sample chamber of the testing machine at $50 \pm 5 \%$ relative humidity and $20 \pm 2{ }^{\circ} \mathrm{C}$ until the fibre reached moisture equilibrium. The time to reach equilibrium (approximately 10-15 min) was previously determined using water vapour desorption/sorption isotherms [39]. The paper frame was cut prior to the beginning of each test.

The clamping length was $10 \mathrm{~mm}$. Fibres were tested at a constant cross head displacement rate of $5 \mu \mathrm{m} \mathrm{s}^{-1}$. The applied force was measured with a load sensor of $2 \mathrm{~N}$ with a resolution of approximately $1 \mathrm{mN}$, and the displacement was measured using an LVDT with a resolution of approximately $0.5 \mu \mathrm{m}$. The sample elongation and the load were recorded continuously. The strain was calculated as the elongation divided by the initial fibre length, taking into account the compliance of the loading frame. A compliance of $35 \mu \mathrm{m} \mathrm{N}^{-1}$ was calculated using glass fibres and the same paper frame and glue for gauge lengths from 3 to $50 \mathrm{~mm}$. Thus, the frame stiffness was at least 15 times higher than the mean single hemp fibre's stiffness.

During tensile loading, optical observations were performed using a digital camera to detect the slippage of the fibre in the clamping area. In such a case, the test was rejected.

The effective cross section was determined using the mean external width, assuming that the fibre was to be perfectly cylindrical and the lumen area neglected. The stress was calculated using the applied force and the evaluated initial cross section mean value of the fibre. The variation of the cross section during the tensile loading was neglected. The tensile strength $\left(\sigma_{R}\right)$ and the strain at failure $\left(\varepsilon_{R}\right)$ were determined, and the apparent tangent modulus of rigidity $(E)$ was computed from the linear section of the last part of the stress-strain curve.

The mean values and standard deviation of these tensile properties were computed for each batch of fibres. Considering the highly skewed distribution that is generally observed for the tensile properties of plant fibres, a statistical analysis was also performed. The best distribution function for each property was identified using Anderson-Darling and Cramer-von Mises tests (implemented in EXTREMES ${ }^{\circledR} 1.1$ software) by minimising the criterion of distances from the distribution diagram. The distribution functions were selected among the classical ones, such as normal, lognormal, exponential, gamma, beta and Weibull laws. Lognormal $(\log N(\mu, \lambda))$ and normal $(N(\mu, \lambda))$ distributions (Eqs. 2, 3) were found to be more realistic and are preferred to the other distributions. These distributions are two parameters of a family of continuous probability distributions. $\mu$ and $\lambda$ are the expectation and standard deviation of $x$ and $\ln (x)$, respectively.

$$
\begin{aligned}
& \log N(\mu, \lambda): f(x)=\frac{1}{x} \frac{1}{\lambda \sqrt{2 \pi}} \mathrm{e}^{\frac{1}{2}\left(\frac{\ln (x)-\mu}{\lambda}\right)^{2}} \\
& N(\mu, \lambda): f(x)=\frac{1}{x} \frac{1}{\lambda \sqrt{2 \pi}} \mathrm{e}^{-\frac{1}{2}\left(\frac{x-\mu}{\lambda}\right)^{2}}
\end{aligned}
$$

\section{Results and discussion}

\section{Colour}

Figure 1 shows photographs of samples from each batch of fibres. A significant difference in colour was 


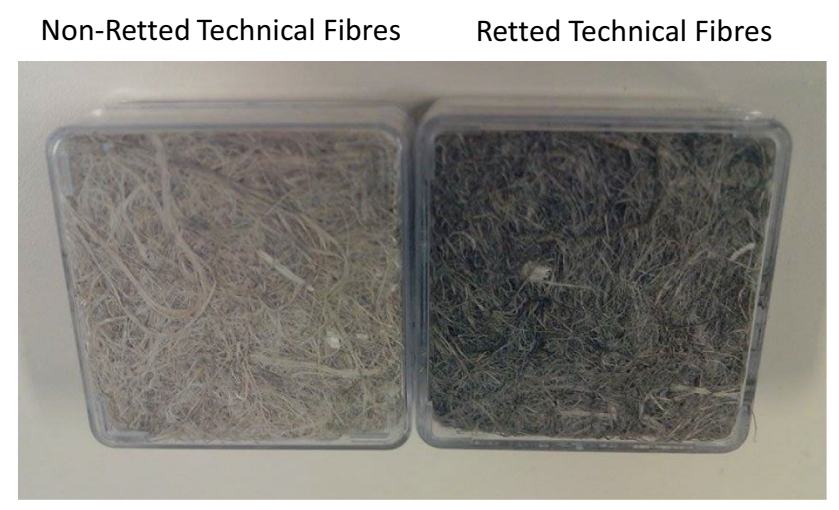

Figure 1 Photographs of the NR-TF (left) and R-TF (right).

Table 1 Colorimetric properties of the fibres

\begin{tabular}{lll}
\hline Colour coordinates & NR-F & R-F \\
\hline Luminance & & \\
L & $63.6 \pm 1.10$ & $53.1 \pm 0.07$ \\
Chrominance & & \\
a & $3.10 \pm 0.12$ & $1.92 \pm 0.01$ \\
b & $12.5 \pm 0.21$ & $6.65 \pm 0.05$ \\
\hline
\end{tabular}

observed. The difference was quantified using spectrophotometry. The measurements (Table 1) indicated that the R-TF was darker $(\Delta L=-10.5)$, slightly greener $(\Delta a=-1.2)$ and less yellow $(\Delta b=-5.85)$ than the NR-TF. The evolutions both in trend and in magnitude were in agreement with the colour values reported by Wang and Postle [40] for a dew-retted hemp variety called Kompolti (grown in Australia). In addition, a similar colour transition from yellow to dark grey with retting was previously observed for flax fibres [41], particularly when a dew retting is used [33]. This darkening in the bundles and fibres was attributed to the microorganisms' metabolic activities that occur during retting [33]. A priori, those effectors are more related to eukaryotic cells (here, the kingdom of fungi), and the recent work of Ribeiro et al. [20] provides features regarding phylogeny and biological taxonomy to facilitate the identification of the effective phylum that influences the retting in the hemp. Unsurprisingly, some prokaryotic cells (bacteria) concomitantly developed with fungi; however, no studies have yet addressed the hypothetical relationships between colour/chemistry under the influence of microorganisms. Additionally, it could be considered that colour determination could be altered by the presence of residual xylem (shives) and/or cuticle remnants on fibres. For example, these contaminant shives are richer in aromatic groups than the bast fibres, and they can have a significant impact on the UV absorption characteristics of a sample [33, 42]. Nonetheless, one could attest to the significant role of fibre lignins, anthocyanin [43] and waxes (lipids with various linkages, such as ester linkages) [12] that could change or condensate due to biotic retting activities.

\section{Morphological and surface properties}

\section{Morphology}

The impact of the retting on the morphologies of the fibre elements (elementary fibres and bundles) was addressed qualitatively by direct microscopy observations (Fig. 2) and quantitatively by image analysis (Table 2; Fig. 3).

Qualitatively, the SEM images displayed a representative illustration of the NR-TF and the R-TF elements that were obtained after processing the stalks (Fig. 2a, b). R-TF appeared to present smaller bundles and more decohesion within bundles than NR-TF. However, the presence of very large bundles was still visible in R-TF. The impact of the retting was also quantified by measuring the width of the fibre elements in each batch. For statistical consideration, measurements (both for NR-TF and for R-TF) were performed on a minimum of 8000 elements. A significant decrease in the average width of elements, from $56 \mu \mathrm{m}$ for NR-TF to $48 \mu \mathrm{m}$ for R-TF, was observed (see Table 2). Figure 3 shows the width histogram of the elements for each batch of fibres. The typical width ranged between 5 and $140 \mu \mathrm{m}$ for both batches, and a lognormal distribution offered the more realistic fit to the width measurements. The same observation was made by Virk [44] for jute fibres. A general shift of the distribution of the R-TF widths to the left (to the smaller diameters) compared to the NR-TF can be observed in Fig. 3. For NR-TF, $75 \%$ of the elements had a diameter between 20 and $85 \mu \mathrm{m}$, whereas $75 \%$ of elements were distributed between 5 and $70 \mu \mathrm{m}$ for R-TF. Therefore, a significant increase in the quantity of elements that had the smallest widths (between 5 and $40 \mu \mathrm{m}$ ) was measured for R-TF. This width range is arguably that of typical elementary primary hemp fibres [43]. 

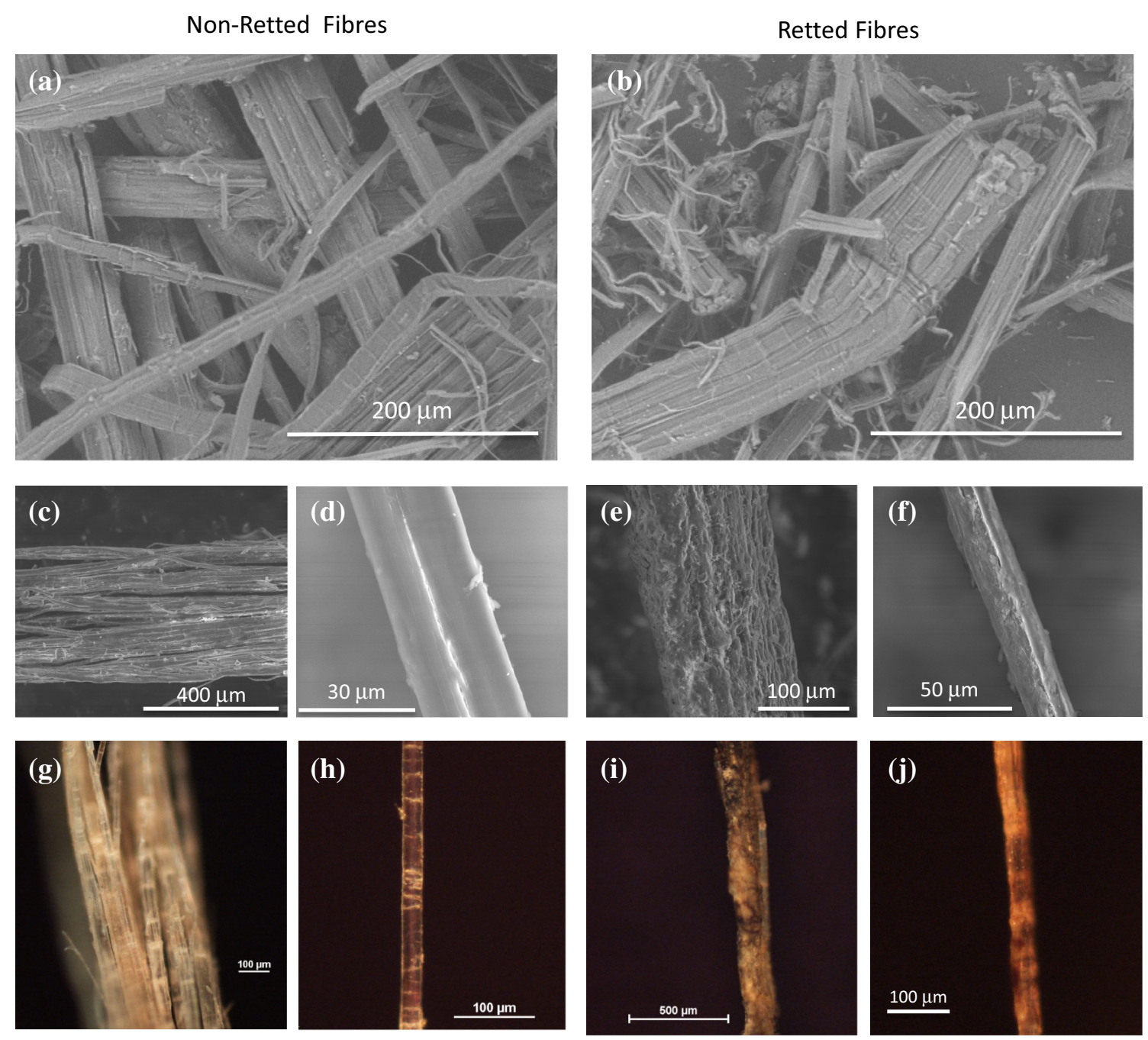

Figure 2 Optical and electron microscopy images of the non-retted (left) and retted (right) fibres.

This result confirms the positive effect of retting on the inter-fibre decohesion within bundles and thus on the fibre individualisation of the industrial hemp. The quantity of elements that were approximately $80 \mu \mathrm{m}$ in width (the class of $86 \mu \mathrm{m}$ in Fig. 3) was approximately the same for both NR-TF and R-TF. These elements, which could contain more than 4-5 individual fibres, appeared to be the least sensitive to the retting process, at least in terms of individualisation.

\section{Surface roughness}

Because surface roughness can contribute to the adhesion between the matrix of choice and the fibres, it is of crucial importance to check its evolution after retting. The surface roughness of the R-SF ( $\mathrm{Sa}=2.05 \mu \mathrm{m}, \mathrm{Sq}=2.6 \mu \mathrm{m})$ was higher than that of the NR-SF ( $\mathrm{Sa}=1.4 \mu \mathrm{m}, \mathrm{Sq}=1.7 \mu \mathrm{m})$; see Table 2 and Fig. 4. These roughness values are consistent with the data collected on other plant fibres, such as the Sa of $3.2 \mu \mathrm{m}$ that was measured by Fuentes et al. [45] on bamboo fibres. This evolution in roughness arguably reflects the cell wall degradation that occurs during retting due to the hydrolytic activities of the effector arsenal that is secreted by the microorganisms. A comparable trend was reported [46] by exploring the effects of both enzymatic and chemical effectors using AFM techniques. But, this roughness increase cannot be directly considered as a positive impact of this unintended retting since it is arguably due to the presence of particles with certainly a low bonding with the wall. 
Table 2 Morphological and surface properties of the fibres

\begin{tabular}{lcc}
\hline & NR-F & R-F \\
\hline Average width of fibre elements $(\mu \mathrm{m})$ & $56 \pm 1.5$ & $48 \pm 0.3$ \\
Sa $(\mu \mathrm{m})$ & $1.40 \pm 0.73$ & $2.05 \pm 0.80$ \\
Sq $(\mu \mathrm{m})$ & $1.70 \pm 0.84$ & $2.60 \pm 1.00$ \\
\hline
\end{tabular}

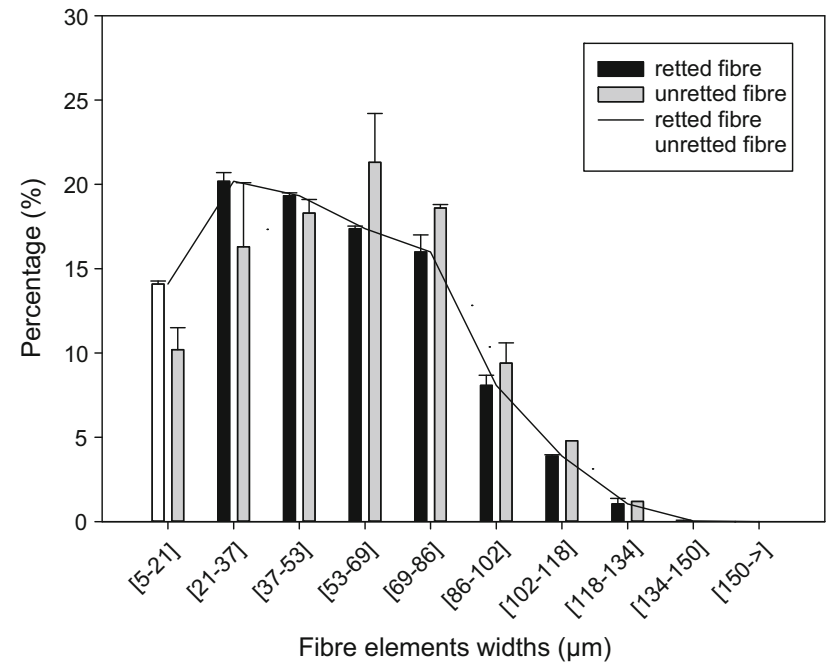

Figure 3 Width distributions of the non-retted and retted fibres.

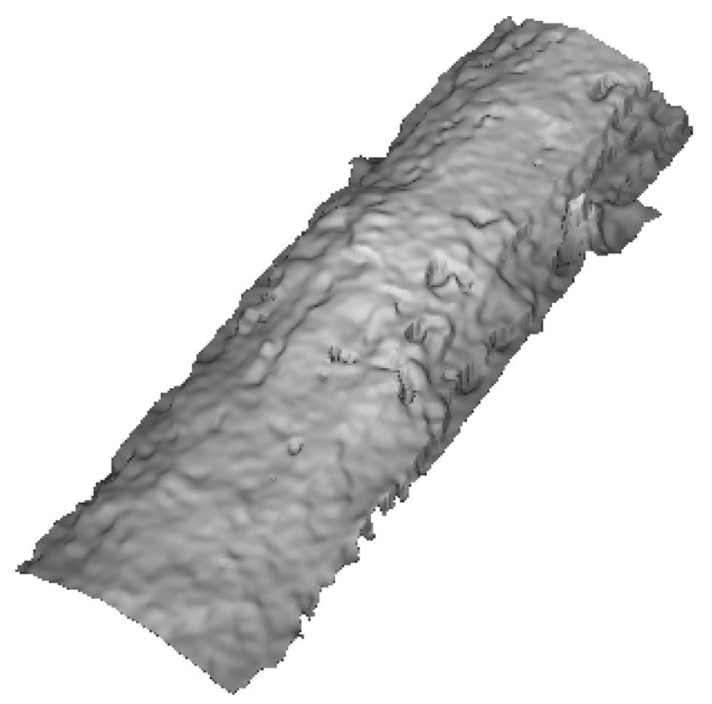

Figure 4 3D surface roughness map of a retted elementary fibre $(\mathrm{Sa}=1.85 \mu \mathrm{m})$.

\section{Elemental composition of the surface}

The elemental composition of the outer surfaces of technical and single fibres was characterised for nonretted and retted fibres using $X$-ray energy-dispersive spectroscopy. The main elements that composed the surface of the fibres were carbon and oxygen (hydrogen cannot be detected by EDS); refer to Fig. 5 . Other elements that were present in small amounts include sodium, magnesium, alumina, silicon, phosphorus, sulphur, chlorine, potassium, calcium, chromium and iron, which might have come from the soil or from fertilisers for plant nutrition. More details about these minerals can be found in a recent review by Amaducci et al. [47]. Figure 5 shows that the TFs had high contents of potassium and calcium (Fig. 5a, b) compared to the SFs (Fig. 5c, d). These elements are essential for plant metabolism and various physiological processes related to growth [48, 49]. Calcium ions, in particular, have been reported to act as bridges, thus linking pectin molecules [50]. In the middle lamella, calcium ions and possibly other cations hold together the cross-linking network of the pectic polysaccharides to function in cell adhesion [51]. In the SFs, the middle lamella was mainly degraded, and this can explain why the amounts of calcium and potassium were low at the surfaces of such fibres (Fig. 5c, d).

At the scale of TFs, it was observed that retting induced a significant decrease in the amount of potassium. This macronutrient is provided to the hemp in fertilisers, and a recent report has shown that $75 \%$ of the potassium can be concentrated in the bast part of the plant [52]. Because potassium is of crucial interest for fungal metabolism (physiology, enzyme activities, etc.), those lignocellulosic decomposers have several uptake transporters [53]; therefore, this decrease is arguably the result of the colonisation of the microorganisms during dew retting.

\section{Biochemical composition}

The masses of two of the fibres' major components, i.e. carbohydrates and lignins, were determined for each batch of fibres (retted and non-retted). Neutral and acidic carbohydrates were identified and quantified by HPLC, and the lignin content was determined using the Klason method. The main values are presented in Table 3. 
(a)

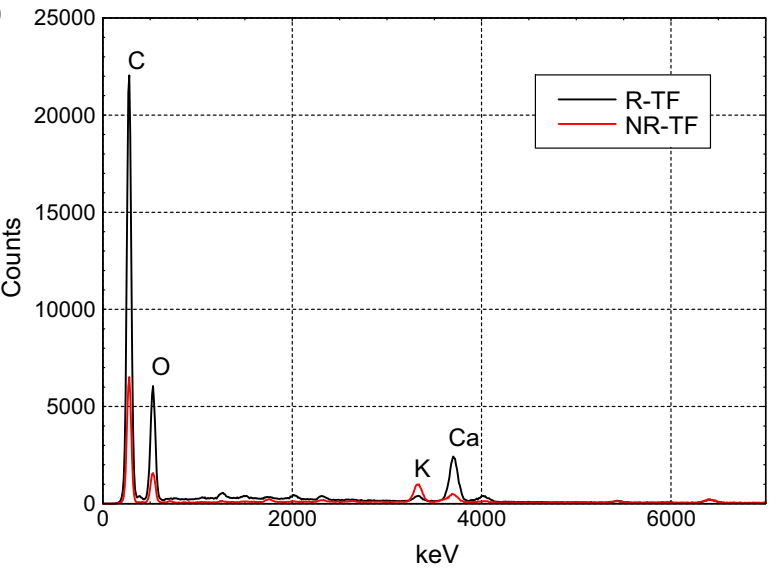

(b)

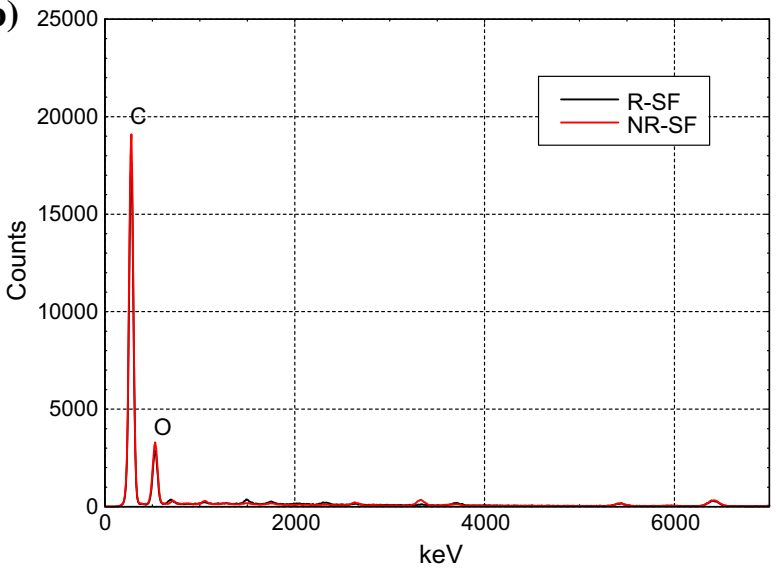

Figure 5 EDS spectra of the non-retted and retted fibres at the scale of technical (a) and single (b) fibres.

Table 3 Carbohydrate and Klason lignin contents of the technical fibres, expressed as percentage of dry matter

\begin{tabular}{lll}
\hline & NR-TF & R-TF \\
\hline Total carbohydrate content & $80.7 \pm 2.5$ & $78.5 \pm 1.8$ \\
Klason Lignin & $4.90 \pm 0.2$ & $6.90 \pm 0.4$ \\
\hline
\end{tabular}

The carbohydrates of the NR-TF and R-TF were the main components, contributing to approximately $80 \%$ of the dry matter material. This carbohydrate content is in agreement with previous values reported in the literature [22,54-57]. A decrease in carbohydrates could have been expected for the retted materials. The variation in the relative part of the total carbohydrates between NR-TF and R-TF was not statistically significant $(P$ value $>0.05)$. Clearly, the total carbohydrate content was not the most useful indicator, although it was highlighted in previous studies [22, 56, 57].

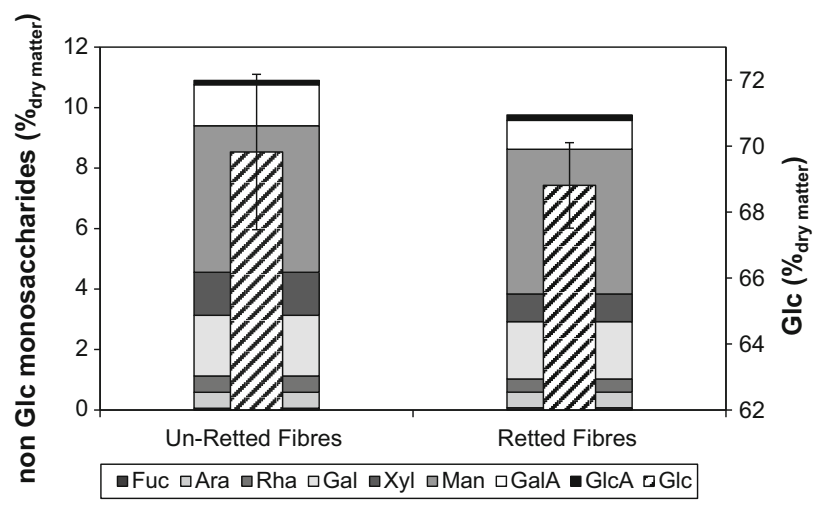

GlcA: glucuronic acid, GalA: galacturonic acid, Man: mannose, Xyl: xylose, Gal: galactose, Rha: rhamnose, Ara: arabinose, Fuc: Fucose

Figure 6 Relative contents of monosaccharides in the non-retted and retted fibres. GlcA glucuronic acid, GalA galacturonic acid, Man mannose, Xyl xylose, Gal galactose, Rha rhamnose, Ara arabinose, Fuc fucose.

Herein, we propose a more precise investigation of the variation in the relative monosaccharides rather than the total carbohydrate amount.

First, the main carbohydrate was glucose (Fig. 6, see the inner bars), accounting for approximately $69 \%$ of the dry matter for retted and non-retted fibres. Jankauskiené et al. [56] reported a slightly higher cellulosic-related value. Liu et al. found very similar values, with slight glucose loss after retting [57]. Notably, the same order of magnitude was found in the study by Liu et al. [57] and in the present work, both of which were based on a similar quantification technique (HPLC), whereas Jankauskienè et al. [56] used the sequential degradative Van Soest technique. Based on the analytical technique used in our work, it can be concluded that this cellulosic part (composed of glucose) did not appear to be significantly metabolised during retting because no significant variation in its content was observed.

Second, and in contrast, the minor carbohydrates (with respect to mass) appeared to be notably degraded by retting (approximately 10\% of the relative part). These minor carbohydrates are related to hemicelluloses and pectic substances, and they represented a mean value of $10.9 \%$ of the dry matter for NR-TF. This value is higher than the one reported by Jankauskiene et al. [56] and is comparable with the data from $[22,57]$.

Third after retting, the hemicelluloses and pectic substances represented only $9.8 \%$ on average, and the $1.1 \%$ loss of dry matter mass was not homogeneous among the monosaccharides. According to Liu et al., 

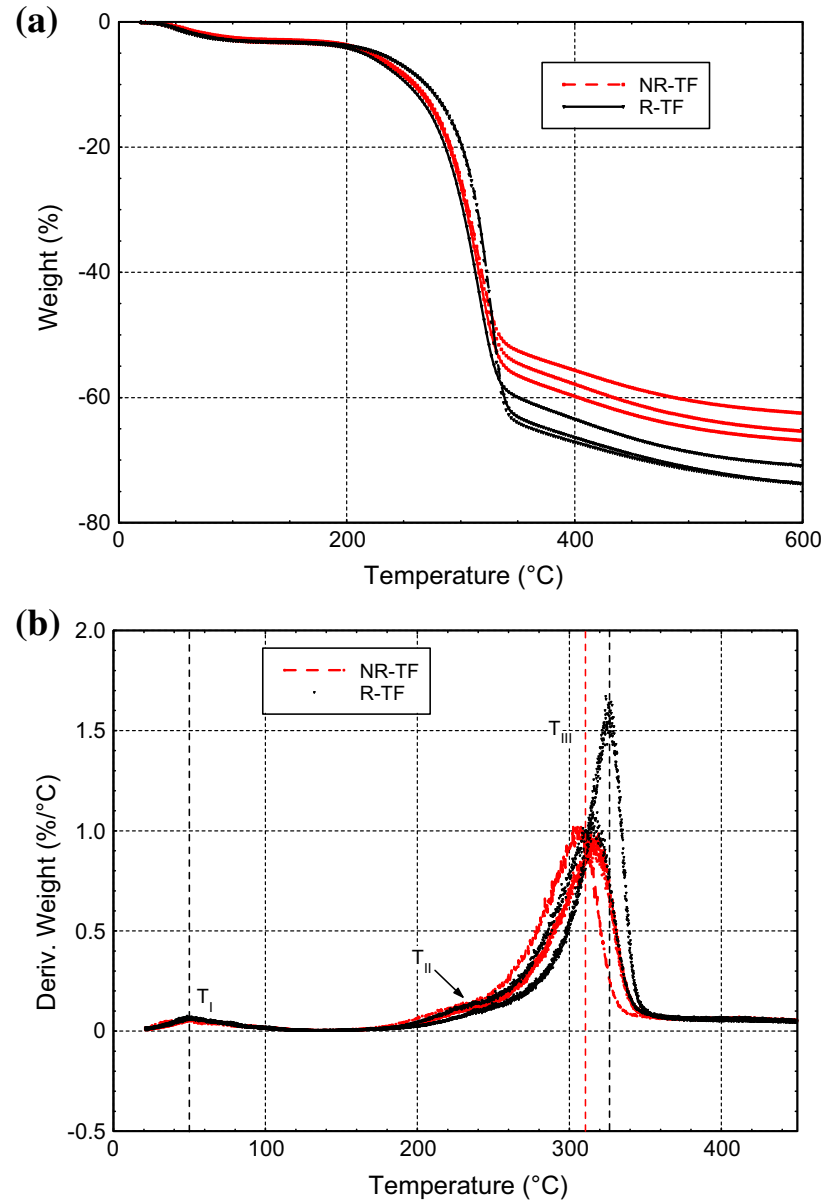

Figure 7 TGA (a) and DTGA (b) curves of non-retted and retted fibres.

(galacturonic acid) GalA, (xylose) Xyl and (rhamnose) Rha are the most affected by the dew retting [22], as well as the fungal retting inoculation method used [57]. Our results are mostly in agreement (see above) with this report. In more detail (Fig. 6, outer bars), in our study, the relative content of $\mathrm{Xyl}$ was divided almost by a factor 2 after retting. The GalA acid and the Rha monomers lost approximately 35 and $20 \%$ in their relative contents, respectively. Both are often assimilated as pectic substances, polygalacturonic acid and rhamnogalacturonan of type I, respectively, as demonstrated in hemp [58] and similarly with flax bast fibre. Pectins that are related to carbohydrates are preferentially located in the middle lamella [58], the wall sublayers that are mainly targeted by the enzymes of microorganisms $[42,57]$ during retting. Xyl could be derived from hemicelluloses, which are generally located in the primary and/or secondary cell wall, where they play a major role in cell wall architecture $[59,60]$. Their reduction could be approached from the difference in mechanical properties between retted and non-retted fibres.

Regarding lignins, a Klason lignin content mean value of $4.9 \%$ of the dry matter (Table 3 ) was quantified for NR-TF, which is in full agreement with values previously reported by Liu et al. using the same Klason technique [22, 57], which consisted of approximately 4-6\% DM.

Quite surprising is the apparent increase in the relative content of lignin in R-TF, with $6.9 \%$ of the dry matter. This was previously observed by Liu et al. $[22,57]$, who measured a steady increase in the relative content of lignin as a function of hemp retting duration and also in the dew retting condition compared to [56]. They suggested that the lignin content becomes concentrated during the retting period due to a lower rate in degradation compared to carbohydrates. In other words, the apparent increase in the lignin content could be due to a substantial loss of other components (soluble extractables, carbohydrates, etc.) occurring in parallel, whereas minimal to no loss of lignin actually occurs at the same time. Another explanation could be related to the Klason lignin method. Non-hydrolysable acid residues remaining after sulphuric acid hydrolysis are quantified. This means that this worldwide Klason method is not sufficiently specific to only quantify lignin moieties. It has been well described that the amount of condensate/non-condensate and acidsoluble/acid-insoluble lignin fractions modulates Klason lignin values [61] and is arguably modulated during retting deconstruction. Additionally, the Klason lignin quantification likely quantifies other phenolic or protein components that evolve during retting; those can be weighed under specific conditions, thus overestimating the lignin content in R-TF.

In addition to these classical biochemical measurements, the cellulose organisation was also characterised using X-ray scattering. The cellulose crystallinity was determined from the X-ray diffractograms using the Rietveld method. A significant decrease in the crystallinity index from $77.5 \%$ for NRTF to $72.8 \%$ for R-TF was observed. Therefore, even if the level of glucose was not significantly altered by retting, the cellulose organisation was partially disordered following the potential reduction by two of the level of Xyl, which could be produced from hemicellulose. This result is of paramount 
importance because the fibre mechanical properties could be negatively impacted. A decrease in the fraction of crystalline cellulose could be the first indication of cell wall modification induced by retting.

\section{Thermal stability}

Thermogravimetric analysis was used to measure the weight loss of the fibres as a function of increasing temperature. Weight loss in fibres occurs due to the evaporation of volatile matter and the decomposition of the fibre wall constituents. The weight losses were plotted for each sample from each batch as a function of the increasing temperature, as depicted in Fig. 7a. The first mass loss, between $30^{\circ} \mathrm{C}$ and $100{ }^{\circ} \mathrm{C}$ with a peak at approximately $50{ }^{\circ} \mathrm{C}\left(T_{\mathrm{I}}\right)$, was attributed to moisture evaporation. The thermal decomposition of the fibres began at approximately $200{ }^{\circ} \mathrm{C}$ [62] and then followed a major loss of weight where the main devolatilisation occurred; it was essentially complete by approximately $350-400{ }^{\circ} \mathrm{C}$.

By calculating the derivative of the weight loss as a function of temperature (Fig. 7b), two areas of weight loss can be clearly observed, thus producing two peaks on the DTGA curves: one between 180 and $280{ }^{\circ} \mathrm{C}\left(T_{\mathrm{II}}\right)$ and the other one, which is the major one

Table 4 Summary of the thermal analysis for both the non-retted and retted fibres

\begin{tabular}{lrr}
\hline & \multicolumn{1}{l}{ NR-F } & \multicolumn{1}{c}{ R-F } \\
\hline TI $\left({ }^{\circ} \mathrm{C}\right)$ & $53.0 \pm 5.3$ & $50.7 \pm 2.2$ \\
Weight loss (\%) @ $110^{\circ} \mathrm{C}$ & $2.80 \pm 0.2$ & $3.0 \pm 0.2$ \\
TIII $\left({ }^{\circ} \mathrm{C}\right)$ & $318 \pm 1.0$ & $323 \pm 3.3$ \\
Weight loss $(\%) @ 340^{\circ} \mathrm{C}$ & $53.5 \pm 1.9$ & $60.0 \pm 1.2$ \\
\hline
\end{tabular}

in terms of both weight loss and thermal spreading, between 300 and $350{ }^{\circ} \mathrm{C}\left(T_{\text {III }}\right)$. These two peaks of the constituents' decomposition are partially superimposed on the temperature scale. The weight at the final temperature represents the char.

The decomposition process of the fibres can be analysed and interpreted using the TGA collected in the literature on the separate constituents of wood and plant fibres, i.e. on cellulose, hemicellulose and lignin $[63,64]$. Under inert conditions, the cellulose decomposition process is very mild until approximately $250{ }^{\circ} \mathrm{C}$ (the stage up to this temperature generally includes a small loss of volatile matter), and cellulose begins to decompose at approximately $325^{\circ} \mathrm{C}$. The main area of weight loss occurs between approximately 325 and $400{ }^{\circ} \mathrm{C}$. The decomposition of the hemicellulose begins at lower temperatures compared to that of cellulose. The analysis of this group of carbohydrates is complex because the process of decomposition varies as a function of the structure and content of the polysaccharides and also of the decomposition products, which can in turn degrade. The thermogram generally presents three stages, including the removal of moisture (from 25 to $180^{\circ} \mathrm{C}$ ) and the decomposition of the majority of the hemicellulosic matter, with rapid weight losses between 180 and $280{ }^{\circ} \mathrm{C}$. In the last stage, from 280 to $500{ }^{\circ} \mathrm{C}$, hemicelluloses and formed by-products decompose, leaving only a char residue. The thermal decomposition of the lignin occurred over a broader temperature range $\left(150-450{ }^{\circ} \mathrm{C}\right)$ than that for cellulose and hemicellulose.

Therefore, for hemp fibres, the first peak in DTGA curves can be attributed to moisture evaporation, the second one to the decomposition of the amorphous polysaccharides (hemicelluloses [65] and pectins) and
Table 5 Mechanical properties of both the nonretted and retted single fibres

\begin{tabular}{|c|c|c|c|c|}
\hline \multirow[t]{2}{*}{ Tensile properties } & \multicolumn{2}{|l|}{ NR-SF } & \multicolumn{2}{|l|}{$\mathrm{R}-\mathrm{SF}$} \\
\hline & $\begin{array}{l}\text { Mean } \pm \text { SD } \\
\text { Min...Max }\end{array}$ & $\begin{array}{l}\text { Distribution law } \\
\mu, \lambda\end{array}$ & $\begin{array}{l}\text { Mean } \pm \text { SD } \\
\text { Min...Max }\end{array}$ & $\begin{array}{l}\text { Distribution law } \\
\mu, \lambda\end{array}$ \\
\hline$E(\mathrm{GPa})$ & $\begin{array}{l}19.7 \pm 10.2 \\
7.5 \ldots 60\end{array}$ & $\begin{array}{l}\log N \\
2.84,0.47\end{array}$ & $\begin{array}{l}16.7 \pm 6.7 \\
8.4 \ldots 39.2\end{array}$ & $\begin{array}{l}\log N \\
2.71,0.38\end{array}$ \\
\hline$\sigma_{\mathrm{R}}(\mathrm{MPa})$ & $\begin{array}{l}410 \pm 215 \\
125 \ldots 1150\end{array}$ & $\begin{array}{l}\log N \\
5.89,0.5\end{array}$ & $\begin{array}{l}345 \pm 200 \\
125 \ldots 1215\end{array}$ & $\begin{array}{l}\log N \\
5.71,0.5\end{array}$ \\
\hline$\varepsilon_{\mathrm{R}}(\%)$ & $\begin{array}{l}3.27 \pm 1.1 \\
0.98 \ldots 6\end{array}$ & $\begin{array}{l}N \\
3.26,1.11\end{array}$ & $\begin{array}{l}3.07 \pm 1.1 \\
1.1 \ldots 6.5\end{array}$ & $\begin{array}{l}N \\
3.07,1.12\end{array}$ \\
\hline Diameter $(\mu \mathrm{m})$ & $\begin{array}{l}22.6 \pm 4.5 \\
14.1 \ldots 36.4\end{array}$ & / & $\begin{array}{l}22.9 \pm 3.0 \\
17.8 \ldots 28.4\end{array}$ & / \\
\hline
\end{tabular}


Figure 8 Probability density and cumulative distribution functions of the tensile properties. (a)
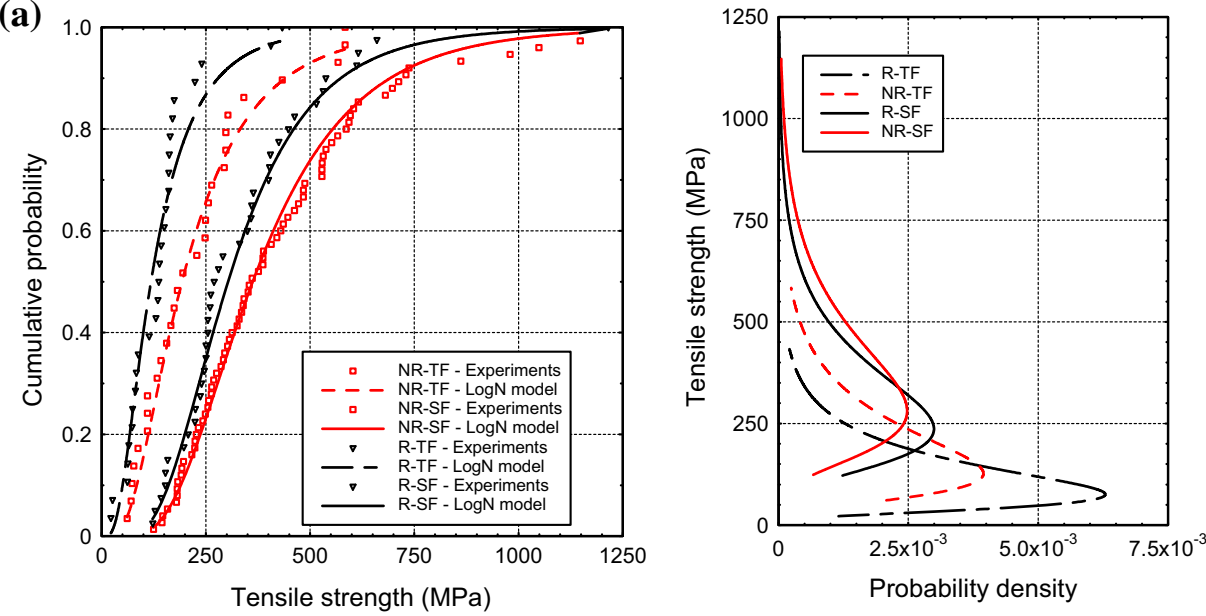

(b)
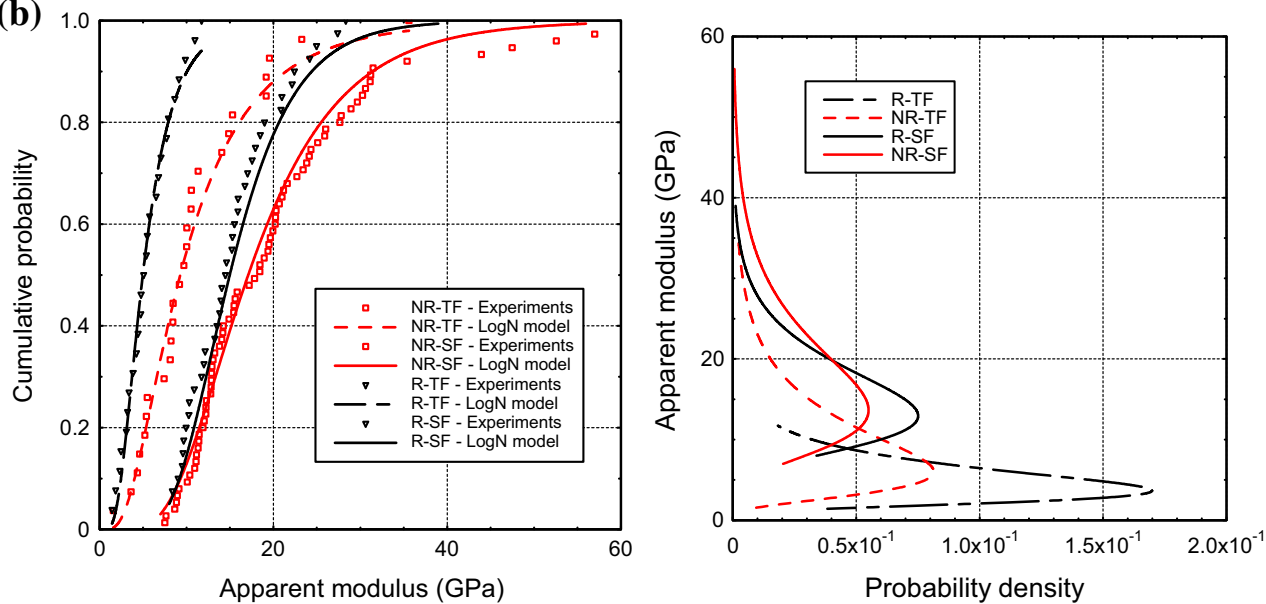

(c)

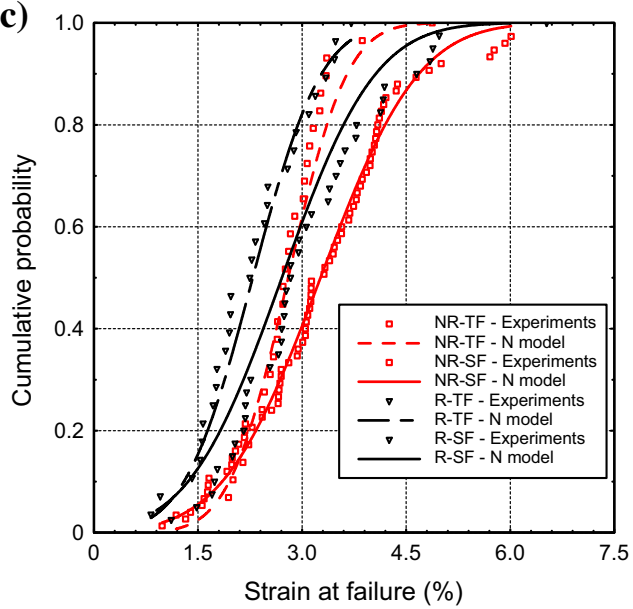

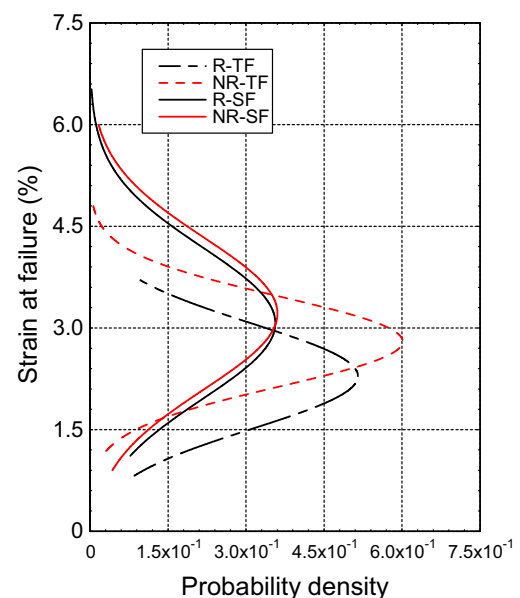

the last one to the decomposition of the cellulose and lignin constituents and the formed by-products. Compared to the data from the literature collected on cellulose, the temperature of cellulose decomposition is lower. Inside the fibre wall, the cellulose stability can be reduced because of interactions with hemicelluloses.

On average, retted fibres displayed a higher decomposition temperature for the third mass loss region (324.5 vs. $318^{\circ} \mathrm{C}$, see Table 4 ) and more weight loss than 
Table 6 Mechanical properties of both the nonretted and retted technical fibres

\begin{tabular}{|c|c|c|c|c|}
\hline \multirow[t]{2}{*}{ Tensile properties } & \multicolumn{2}{|l|}{ NR-TF } & \multicolumn{2}{|l|}{$\mathrm{R}-\mathrm{TF}$} \\
\hline & $\begin{array}{l}\text { Mean } \pm \text { SD } \\
\text { Min...Max }\end{array}$ & $\begin{array}{l}\text { Distribution law } \\
\mu, \lambda\end{array}$ & $\begin{array}{l}\text { Mean } \pm \text { SD } \\
\text { Min...Max }\end{array}$ & $\begin{array}{l}\text { Distribution law } \\
\mu, \lambda\end{array}$ \\
\hline$E(\mathrm{GPa})$ & $\begin{array}{l}11.5 \pm 7.1 \\
3.1 \ldots 29.1\end{array}$ & $\begin{array}{l}\log N \\
2.23,0.65\end{array}$ & $\begin{array}{l}7.6 \pm 4.6 \\
2.3 \ldots 18.8\end{array}$ & $\begin{array}{l}\log N \\
1.6,0.55\end{array}$ \\
\hline$\sigma_{\mathrm{R}}(\mathrm{MPa})$ & $\begin{array}{l}235 \pm 150 \\
60 \ldots 585\end{array}$ & $\begin{array}{l}\log N \\
5.26,0.65\end{array}$ & $\begin{array}{l}145 \pm 95 \\
25 \ldots 435\end{array}$ & $\begin{array}{l}\log N \\
4.77,0.67\end{array}$ \\
\hline$\varepsilon_{\mathrm{R}}(\%)$ & $\begin{array}{l}2.8 \pm 0.66 \\
1.2 \ldots 4.9\end{array}$ & $\begin{array}{l}N \\
2.8,0.66\end{array}$ & $\begin{array}{l}2.3 \pm 0.77 \\
0.8 \ldots 3.7\end{array}$ & $\begin{array}{l}N \\
2.3,0.77\end{array}$ \\
\hline Diameter $(\mu \mathrm{m})$ & $\begin{array}{l}240 \pm 95 \\
116.4 \ldots 479.8\end{array}$ & / & $\begin{array}{l}224 \pm 61 \\
119.5 \ldots 339.5\end{array}$ & / \\
\hline
\end{tabular}

the NR-TF ( 60 vs. $53.5 \%$ at $340{ }^{\circ} \mathrm{C}$ ). This result is consistent with the biochemical analysis. As mentioned previously, retting induces the degradation of hemicelluloses and pectins (decreases in the relative contents of xylose, galacturonic acid and rhamnose monomers), which induces an increase in the relative fraction of the other wall components, and more precisely in lignins. The higher scattering in TGA observed for the retted fibres compared to the non-retted fibres can be attributed to the heterogeneity of the retting process.

\section{Tensile properties}

The tensile properties of the NR-SF (Table 5) were on the same order of magnitude of those determined previously in 2008 and for this range of fibre diameter (approximately $22 \mu \mathrm{m}$ ) and relative humidity $(50 \%$ RH) [5]. The mean apparent tangent Young's modulus was approximately $20 \mathrm{GPa}$, the mean tensile strength was $410 \mathrm{MPa}$, and the strain at failure was $3.27 \%$. Strength and rigidity were well fitted by a lognormal distribution (Fig. 8a and b) and strain at failure by a normal distribution (Fig. 8c). The scattering was also on the same order of magnitude as generally measured for hemp fibres $[5,22,66]$ and other plant fibres such as jute [67], with a coefficient of variation of approximately 40-55\% for the tensile strength and rigidity and $30 \%$ for the strain at failure. This difference in the scattering of tensile properties is primarily explained by the error when determining the effective cross section of the fibre [67]. Even if a nonlinear behaviour has been observed for the tested hemp fibres, as in previous studies [68, 69], the influence of retting on the nonlinear behaviour is beyond the scope of this study.

The tensile properties of TFs were lower than those of SFs. For NR-TF (Table 6), the tensile strength and rigidity were approximately $40 \%$ lower than for SFs and $15 \%$ lower for the strain at failure, for a mean diameter of approximately $240 \mu \mathrm{m}$. This difference can be explained by the complex structure of TFs, which are composed of many SFs glued together by a pectic layer, which is the main target of the retting process when efficient. SFs can be discontinuous along the TF length. Tensile rigidity is thus controlled by both the SF rigidity and the shear transfer at the fibre interface. Compared to SFs, an additional axial strain (induced by the shear deformation and the damage of the pectic layer) and thus a reduced apparent rigidity were observed for the TFs. The decrease in strength can be explained by both the increase in material volume (Weibull theory) and the defects at the interface between the SFs.

Unintended field retting induced a decrease in the mechanical properties of SF with a respective mean loss of $18 \%$ in rigidity, $16 \%$ in strength and $6 \%$ in strain at failure. These decreases in tensile properties could be attributed to the decrease in cellulose crystallinity. A previous study [66] showed, using a modelling approach, that the apparent rigidity of hemp fibres is highly influenced by the fraction of crystalline cellulose. It is one of the most sensitive parameters, along with the longitudinal elastic modulus of the crystalline cellulose, the angle of the cellulose microfibrils and the shear modulus of the amorphous cellulose. A decrease of approximately $10 \%$ in tensile rigidity is predicted with the model (data not shown) when the fraction of crystalline cellulose decreases from 77.5 to $72.8 \%$. Thus, the experimentally observed reduction in the tensile rigidity could be mainly due to the decrease in crystallinity.

This decrease in mechanical properties could also result from the degradation of hemicelluloses (a decrease in the relative content of xylose), which are thought to play an important role in the 3D 
Figure 9 Equilibrium moisture sorption and desorption isotherms of the fibres.

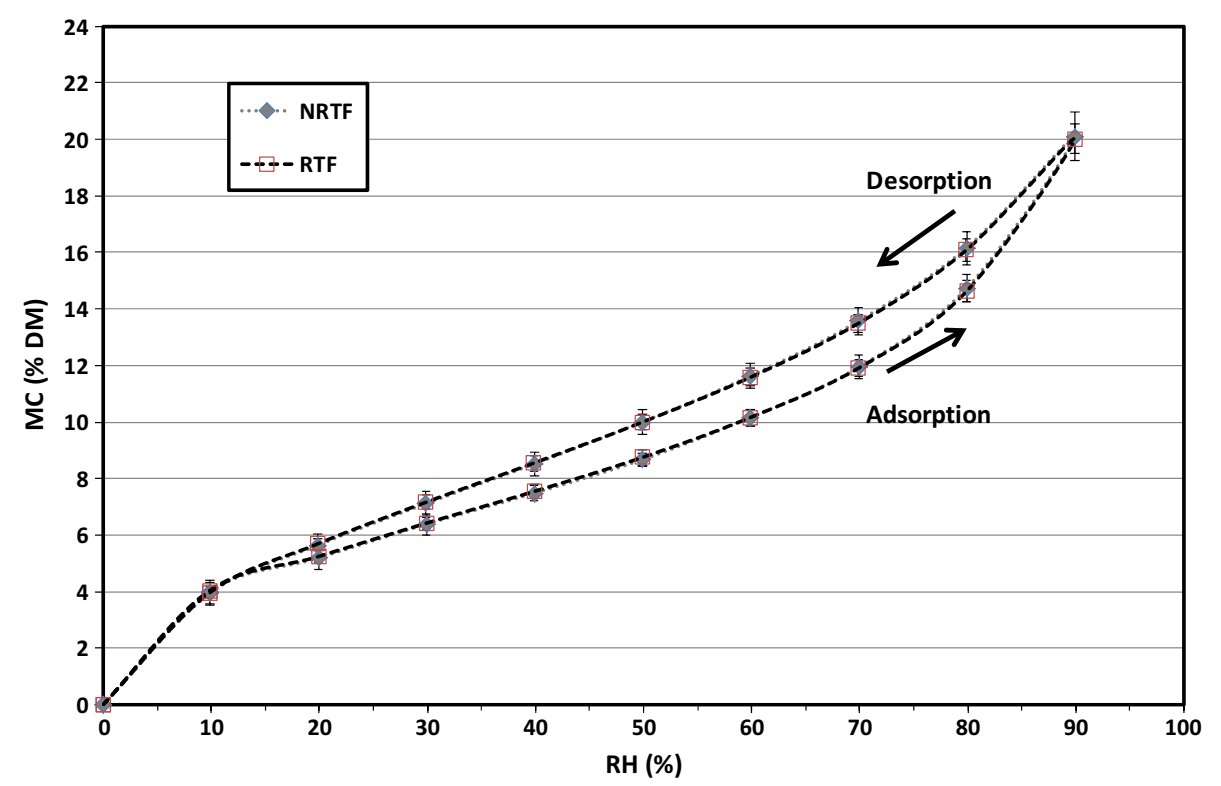

organisation of wall macromolecules and the resulting mechanical performance.

At the scale of TFs, the decrease was higher, with respective decreases of $34 \%$ of $E, 38 \%$ of $\sigma_{\mathrm{R}}$ and $18 \%$ of $\varepsilon_{\mathrm{R}}$. This result could be due to the degradation of the main components of the interface layer (monomers of pectins, such as galacturonic acid, as well as rhamnose monomers).

Liu et al. [22,57] also noted a negative effect of field retting on the mechanical properties of the fibres, but only after extended field retting (i.e. 70 days), which was presumably due to the accelerated degradation of cellulose by the action of microorganisms.

Therefore, it could be hypothesised that the fibres tested in this work could have been processed from straws that had been over-retted. This clearly indicates that non-controlled field retting can be detrimental for the quality of industrial hemp bast fibres and particularly for their mechanical properties. A substantial amount of literature has reported alternatives to dew retting from the perspectives of both better control of quality and better fibre quality, with some works already showing that high-quality fibre can be efficiently obtained by a non-field enzymatic treatment. Dreyer et al. [28] noted that, at this time, the economical barrier to such a process appears more preponderant than the technical engineering limitations.

\section{Water vapour sorption}

The hygroscopic behaviours of the NR-TF and the R-TF were explored by constructing their water sorption isotherms. The water vapour desorption/adsorption isotherms are presented in Fig. 9. Each point corresponds to the equilibrated moisture content obtained at a precise RH level. As expected and as observed for many lignocellulosic materials, as well as for hemp fibres [39], the adsorption/desorption properties of isolated hemp fibres were characterised by a sigmoidal shape of the isotherms and hysteresis between the sorption and desorption loops. This shape results from the combination and the competition of the different involved sorption mechanisms and their kinetics [70, 71]. The first domain $(0-15 / 20 \% \mathrm{RH})$ is generally dominated by the adsorption of water as a monolayer onto the internal surface of the cell wall. The second one $(15 / 20$, up to $70 \% \mathrm{RH})$ is mainly related to polylayer water formation in the transient wall microcapillaries, and the last domain of the sigmoid is related to capillary condensation [70]. Contrary to all expectations, the NR-TF and R-TF sorption curves matched perfectly, regardless of the domain of the isotherm. Effectively, it could have been assumed that the retting step would have suppressed some of the water interaction sites in R-TF, mainly the hydroxyl group of the non-cellulosic polysaccharides that had been metabolised (to recall, see the significant decreases in xylose, rhamnose and galacturonic acid, as depicted in §3.3). The results show that, although the biochemical composition quantified a moderated diminution of some hemicelluloses and pectic polysaccharides in the R-TF, and therefore many possible water-interacting sites (by loss of their hydroxyl functions), the R-TF hygroscopic capacity was still equivalent to the NR-TF 
regarding our samples. This could not be related to a lack of sensitivity of the equipment because the sorption balance had an accuracy of $0.1 \mu \mathrm{g}$. To explain this unexpected equivalent hygroscopic property, a compensation effect can be hypothesised, based on the unmasking water interaction site on R-TF; those sites are hypothetically unavailable in NR-TF. The unmasking would be operated by the enzymatic opening of the wall structures, and neo sites would compensate for the loss of water interacting with the carbohydrate. Precisely, the study of cellulose crystallinity supports this hypothesis of compensation by neo water-interacting groups that are formed due to retting, albeit the significant loss of non-cellulosic water-interacting groups. Indeed, the crystallinity index decrease from 54 to $48 \%$ can be translated to providing as much as a glucopyranosyl group that is supposed to be accessible to interact with water, and thus adsorbing more. Liu et al. [22, 57] observed a decrease in hemp fibre mechanical properties with over-retting, and they hypothesised that this was due to a partial degradation of the cellulose. Here, it was confirmed experimentally by showing that over-retting degraded the cellulose structure (the crystallisation decrease), although a significant loss of glucose might not be quantified.

\section{Conclusions}

This study aimed to fill a gap in the literature focused on the retting effect on industrial hemp bast fibres. To complete the microbial, enzymatic, kinetics and biochemical data already available in the literature, we investigated, in this study, the influence of non-controlled field retting on the properties of TFs. Indeed, at the scale of the laboratory batch and incubators, most of the available data monitored the activity of the effectors (i.e. enzymatic production, microbial development and carbohydrate release) but bypassed the technical characteristics of the fibres thereof. In addition to such characteristics, we showed in this study that retting also induced a change in fibre separation, surface roughness and thermal stability and a decrease in tensile properties.

The results confirm that non-controlled field retting can induce a significant change in several of these physicochemical properties and is detrimental to mechanical properties. This is particularly true when a non-controlled field retting lead to an over-retting as we hypothesised in this work. In line with the conclusions of Liu et al. [22], it is suggested that above-ground controlled methods based on the use of selected enzymes or microorganisms with targeted enzymes have to be widely adopted. Such processing, if economically acceptable, might limit the alteration of the fibre quality and thus the variability in the properties to which non-controlled retting directly contributes to. In the light of these results, it can already be concluded that it should be essential to dispose of a tool indicating how to manage straw quality before the mechanical processing of high-grade fibres. This tool could integrate several parameters such farmer risk, straw and fibre economic values, fibre quality and markets specifications. These results underline that without a method to qualify straw, traditional field retting for hemp does not appear to be a relevant treatment before the mechanical processing of high-grade fibres, whereas it is for others, such as flax. The retting in use for flax has been in practice and under optimisation for eons to significantly increase the fibre technical quality. A similar result is desired for hemp; therefore, additional knowledge about retting management that is not dissociated from the effects on TFs is arguably needed.

\section{Acknowledgements}

The authors thank Francois Gaudard from FARE for his skilful technical assistance in HPLC, lignin quantification and MEB support. The authors also express theirs thanks to Miguel Pernes for the DVS support. Additionally, Justine Padovani is acknowledged for her critical discussion. Roland Salut, Thomas Jeannin and Paul Tourneroche from FEMTO-ST are thanked for their assistance in energy-dispersive $\mathrm{X}$-ray spectroscopy, surface roughness measurements and ATG, respectively, and Virginie Moutarlier from UTINAM is acknowledged for performing XRD measurements. The authors would also like to thank La Chanvrière Company in France for supplying the hemp fibres. Johnny Beaugrand acknowledges the financial support from the CPER MATRICE state-to-country France-Champagne-Ardenne programme.

\section{Compliance with ethical standards}

Conflict of interest The authors declare that they have no conflicts of interest. 


\section{References}

[1] Carus M (2015) World-wide market data on hemp and other bast fibres - status and outlook. In: 12th International conference of the European Industrial Hemp Association (EIHA), Wesseling, Germany, May 20th-21st

[2] Carus M, Karst S, Kauffmann A, Hobson J, Bertucelli S (2013) The European Hemp Industry: cultivation, processing and applications for fibres, shivs and seeds. 10th International Conference of the European Industrial Hemp Association (EIHA), Wesseling, Germany, May 22nd-23rd

[3] Bono P, Le Duc A, Lozachmeur M, Day A (2015) Materials: new fields of research and development for the valorization of technical plant fibers (flax fiber and hemp). OCL 22(6):D613

[4] Placet V (2009) Characterization of the thermo-mechanical behaviour of hemp fibres intended for the manufacturing of high performance composites. Compos Part A Appl Sci Manuf 40(8):1111-1118

[5] Placet V, Cisse O, Boubakar ML (2012) Influence of environmental relative humidity on the tensile and rotational behaviour of hemp fibres. J Mater Sci 47:3435-3446. doi:10. 1007/s10853-011-6191-3

[6] Duval A, Bourmaud A, Augier L, Baley C (2011) Influence of the sampling area of the stem on the mechanical properties of hemp fibers. Mater Lett 65(4):797-800

[7] Thygesen A (2006) Properties of hemp fibre polymer composites - an optimisation of fibre properties using novel defibration methods and fibre characterisation, $\mathrm{PhD}$ Thesis, Risø National Laboratory Roskilde Denmark, p 146

[8] Bourmaud A, Baley C (2007) Investigations on the recycling of hemp and sisal fibre reinforced polypropylene composites. Polym Degrad Stab 92(6):1034-1045

[9] Beckermann GW, Pickering KL (2008) Engineering and evaluation of hemp fibre reinforced polypropylene composites: fibre treatment and matrix modification. Compos Part A Appl Sci Manuf 39(6):979-988

[10] Lu N, Swan RH, Ferguson I (2012) Composition, structure, and mechanical properties of hemp fiber reinforced composite with recycled high-density polyethylene matrix. J Compos Mater 46(16):1915-1924

[11] Madsen B, Thygesen A, Lilholt H (2009) Plant fibre composites - porosity and stiffness. Compos Sci Technol 69(7-8):1057-1069

[12] Thygesen A, Thomsen AB, Daniel G, Lilholt H (2007) Comparison of composites made from fungal defibrated hemp with composites of traditional hemp yarn. Ind Crops Prod 25(2):147-159

[13] Pickering KL, Beckermann GW, Alam SN, Foreman NJ (2007) Optimising industrial hemp fibre for composites. Compos Part A Appl Sci Manuf 38(2):461-468
[14] Shah D (2013) Developing plant fibre composites for structural applications by optimising composite parameters: a critical review. J Mater Sci 48(18):6083-6107. doi:10. 1007/s10853-013-7458-7

[15] Rask M, Madsen B, Sörensen BF, Fife JL, Martyniuk K, Lauridsen EM (2012) In situ observations of microscale damage evolution in unidirectional natural fibre composites. Compos Part A Appl Sci Manuf 43(10):1639-1649

[16] Coroller G, Al Lefeuvre, Le Duigou A, Bourmaud A, Ausias G, Gaudry T, Baley C (2013) Effect of flax fibres individualisation on tensile failure of flax/epoxy unidirectional composite. Compos Part A Appl Sci Manuf 51:62-70

[17] Hernandez-Estrada A, Gusovius H-J, Müssig J, Hughes M (2016) Assessing the susceptibility of hemp fibre to the formation of dislocations during processing. Ind Crops Prod 85:382-388

[18] Franck RR (ed) (2005) Bast and other plant fibres. Woodhead Publishing, Boca Raton, USA

[19] Akin DE, Condon B, Sohn M, Foulk JA, Dodd RB, Rigsby LL (2007) Optimization for enzyme-retting of flax with pectate lyase. Ind Crops Prod 25(2):136-146

[20] Ribeiro A, Pochart P, Day A, Mennuni S, Bono P, Baret J-L, Spadoni J-L, Mangin I (2015) Microbial diversity observed during hemp retting. Appl Microbiol Biotechnol 99(10):4471-4484

[21] Sharma HSS, van Sumere CF (1992) The biology and processing of flax. M Publications, Belfast, Northern Ireland

[22] Liu M, Fernando D, Daniel G, Madsen B, Meyer AS, Ale MT, Thygesen A (2015) Effect of harvest time and field retting duration on the chemical composition, morphology and mechanical properties of hemp fibers. Ind Crops Prod 69:29-39

[23] Liu M, Meyer AS, Fernando D, Silva DAS, Daniel G, Thygesen A (2016) Effect of pectin and hemicellulose removal from hemp fibres on the mechanical properties of unidirectional hemp/epoxy composites. Compos A Appl Sci Manuf 90:724-735

[24] Liu M, Silva DAS, Fernando D, Meyer AS, Madsen B, Daniel G, Thygesen A (2016) Controlled retting of hemp fibres: effect of hydrothermal pre-treatment and enzymatic retting on the mechanical properties of unidirectional hemp/ epoxy composites. Compos Part A Appl Sci Manuf $88: 253-262$

[25] Sisti L, Totaro G, Vannini M, Fabbri P, Kalia S, Zatta A, Celli A (2016) Evaluation of the retting process as a pretreatment of vegetable fibers for the preparation of highperformance polymer biocomposites. Ind Crops Prod 81:56-65

[26] Di Candilo M, Bonatti PM, Guidetti C, Focher B, Grippo C, Tamburini E, Mastromei G (2010) Effects of selected 
pectinolytic bacterial strains on water-retting of hemp and fibre properties. J Appl Microbiol 108(1):194-203

[27] Di Candilo M, Ranalli P, Bozzi C, Focher B, Mastromei G (2000) Preliminary results of tests facing with the controlled retting of hemp. Ind Crops Prod 11(2-3):197-203

[28] Dreyer J, Müssig J, Koschke N, Ibenthal WD, Harig H (2002) Comparison of enzymatically separated Hemp and Nettle fibre to chemically separated and steam exploded hemp fibre. J Ind Hemp 7(1):43-59. doi:10.1300/ J237v07n01 05

[29] Li Y, Pickering KL, Farrell RL (2009) Analysis of green hemp fibre reinforced composites using bag retting and white rot fungal treatments. Ind Crops Prod 29(2-3):420-426

[30] Thygesen A, Liu M, Meyer AS, Daniel G (2013) Hemp fibres: enzymatic effect of microbial processing on fibre bundle structure. In: Risoe international symposium on materials science. Proceedings, 2013. Forskningscenter Risoe Materialeforskning, pp 373-380

[31] Valladares Juarez AG, Dreyer J, Göpel PK, Koschke N, Frank D, Märkl H, Müller R (2009) Characterisation of a new thermoalkaliphilic bacterium for the production of highquality hemp fibres, Geobacillus thermoglucosidasius strain PB94A. Appl Microbiol Biotechnol 83(3):521-527

[32] Saleem Z, Rennebaum H, Pudel F, Grimm E (2008) Treating bast fibres with pectinase improves mechanical characteristics of reinforced thermoplastic composites. Compos Sci Technol 68(2):471-476

[33] Akin DE, Epps HH, Archibald DD, Sharma HSS (2000) Color measurement of flax retted by various means. Text Res J 70(10):852-858

[34] Berzin F, Vergnes B, Beaugrand J (2014) Evolution of lignocellulosic fibre lengths along the screw profile during twin screw compounding with polycaprolactone. Compos Part A Appl Sci Manuf 59:30-36

[35] Monties B (1984) Dosage de la lignine insoluble en milieu acide: influence du prétraitement par hydrolyse acide sur la lignine Klason de bois et de paille. Agronomie 4(4):387-392

[36] Beaugrand J, Chambat G, Wong VWK, Goubet F, Rémond $\mathrm{C}$, Paès $\mathrm{G}$, Benamrouche $\mathrm{S}$, Debeire $\mathrm{P}$, Donohue $\mathrm{MO}$, Chabbert B (2004) Impact and efficiency of GH10 and GH11 thermostable endoxylanases on wheat bran and alkaliextractable arabinoxylans. Carbohydr Res 339(15):2529-2540

[37] Beaugrand J, Nottez M, Konnerth J, Bourmaud A (2014) Multi-scale analysis of the structure and mechanical performance of woody hemp core and the dependence on the sampling location. Ind Crops Prod 60:193-204

[38] Thygesen A, Oddershede J, Lilholt H, Thomsen AB, Stahl K (2005) On the determination of crystallinity and cellulose content in plant fibres. Cellulose 12(6):563-576
[39] Guicheret-Retel V, Cisse O, Placet V, Beaugrand J, Pernes M, Boubakar ML (2015) Creep behaviour of single hemp fibres. Part II: influence of loading level, moisture content and moisture variation. J Mater Sci 50(5):2061-2072. doi:10.1007/s10853-014-8768-0

[40] Wang HM, Postle R (2004) Improving the color features of hemp fibers after chemical preparation for textile applications. Text Res J 74(9):781-786

[41] Martin N, Mouret N, Davies P, Baley C (2013) Influence of the degree of retting of flax fibers on the tensile properties of single fibers and short fiber/polypropylene composites. Ind Crops Prod 49:755-767

[42] Akin DE (2013) Linen most useful: perspectives on structure, chemistry, and enzymes for retting flax. ISRN Biotechnol 2013:186534. doi:10.5402/2013/186534

[43] Müssig J (2010) Industrial applications of natural fibres: structure, properties and technical applications. doi:10.1002/ 9780470660324

[44] Virk A (2010) Numerical models for natural fibre composites with stochastic properties, PhD Thesis, University of Plymouth, UK, p 115

[45] Fuentes CA, Brughmans G, Tran LQN, Dupont-Gillain C, Verpoest I, Van Vuure AW (2015) Mechanical behaviour and practical adhesion at a bamboo composite interface: physical adhesion and mechanical interlocking. Compos Sci Technol 109:40-47

[46] George M, Mussone PG, Abboud Z, Bressler DC (2014) Characterization of chemically and enzymatically treated hemp fibres using atomic force microscopy and spectroscopy. Appl Surf Sci 314:1019-1025

[47] Amaducci S, Scordia D, Liu FH, Zhang Q, Guo H, Testa G, Cosentino SL (2015) Key cultivation techniques for hemp in Europe and China. Ind Crops Prod 68:2-16

[48] Fromm J (2010) Wood formation of trees in relation to potassium and calcium nutrition. Tree Physiol 30(9):1140-1147

[49] Hepler PK (2005) Calcium: a central regulator of plant growth and development. Plant Cell 17(8):2142-2155

[50] Akin DE, Henriksson G, Morrison WH, Eriksson K-EL (1998) Enzymatic retting of flax. In: Enzyme applications in fiber processing. ACS symposium series, 687 edn. American Chemical Society, pp 269-278

[51] Willats WT, McCartney L, Mackie W, Knox JP (2001) Pectin: cell biology and prospects for functional analysis. Plant Mol Biol 47(1-2):9-27

[52] Finnan J, Burke B (2013) Potassium fertilization of hemp (Cannabis sativa). Ind Crops Prod 41:419-422

[53] Benito B, Garciadeblás B, Fraile-Escanciano A, RodríguezNavarro A (2011) Potassium and sodium uptake systems in 
fungi. The transporter diversity of Magnaporthe oryzae. Fungal Genet Biol 48(8):812-822

[54] Fischer H, Müssig J (2010) Bast fibre processing and uses. In: Singh B (ed) Industrial crops and uses, p 326

[55] Marrot L, Lefeuvre A, Pontoire B, Bourmaud A, Baley C (2013) Analysis of the hemp fiber mechanical properties and their scattering (Fedora 17). Ind Crops Prod 51:317-327

[56] Jankauskienė Z, Butkutė B, Gruzdevienè E, Cesevičienė J, Fernando AL (2015) Chemical composition and physical properties of dew- and water-retted hemp fibers: Advances in Industrial Crops and Products Worldwide: AAIC 2014 international conference. Ind Crops Prod 75:206-211

[57] Liu M, Fernando D, Meyer AS, Madsen B, Daniel G, Thygesen A (2015) Characterization and biological depectinization of hemp fibers originating from different stem sections. Ind Crops Prod 76:880-891

[58] Blake A, Marcus S, Copeland J, Blackburn R, Knox JP (2008) In situ analysis of cell wall polymers associated with phloem fibre cells in stems of hemp, Cannabis sativa L. Planta 228(1):1-13

[59] Bauer S (2012) Mass spectrometry for characterizing plant cell wall polysaccharides. Front Plant Sci 3:45. doi:10.3389/ fpls.2012.00045

[60] Carpita NC, Gibeaut DM (1993) Structural models of primary cell walls in flowering plants: consistency of molecular structure with the physical properties of the walls during growth. Plant J 3(1):1-30

[61] Yasuda S, Fukushima K, Kakehi A (2001) Formation and chemical structures of acid-soluble lignin I: sulfuric acid treatment time and acid-soluble lignin content of hardwood. J Wood Sci 47(1):69-72

[62] Beaugrand J, Berzin F (2013) Lignocellulosic fiber reinforced composites: influence of compounding conditions on defibrization and mechanical properties. J Appl Polym Sci 128(2):1227-1238
[63] Williams PT, Besler S (1993) Thermogravimetric analysis of the components of biomass. In: Bridgwater AV (ed) Advances in thermomechanical biomass conversion, vol 1 . Springer, Dordrecht, pp 711-782

[64] Kabir MM (2012) Effects of chemical treatments on Hemp fibre reinforced polyester composite. University of Southern Queensland, Australia

[65] Ouajai S, Shanks RA (2005) Composition, structure and thermal degradation of hemp cellulose after chemical treatments. Polym Degrad Stab 89(2):327-335. doi:10.1016/j. polymdegradstab.2005.01.016

[66] Placet V, Trivaudey F, Cisse O, Gucheret-Retel V, Boubakar ML (2012) Diameter dependence of the apparent tensile modulus of hemp fibres: a morphological, structural or ultrastructural effect? Compos Part A Appl Sci Manuf 43(2):275-287

[67] Virk AS, Hall W, Summerscales J (2010) Failure strain as the key design criterion for fracture of natural fibre composites. Compos Sci Technol 70(6):995-999

[68] Placet V, Cisse O, Boubakar L (2014) Nonlinear tensile behaviour of elementary hemp fibres. Part I: investigation of the possible origins using repeated progressive loading with in situ microscopic observations. Compos Part A Appl Sci Manuf 56:319-327

[69] Placet V, Cisse O, Boubakar ML (2012) Influence of environmental relative humidity on the tensile and rotational behaviour of hemp fibres. J Mater Sci 47(7):3435-3446. doi:10.1007/s10853-011-6191-3

[70] Hill CAS, Norton A, Newman G (2009) The water vapor sorption behavior of natural fibers. J Appl Polym Sci 112(3):1524-1537

[71] Bessadok A, Langevin D, Gouanvé F, Chappey C, Roudesli S, Marais S (2009) Study of water sorption on modified Agave fibres. Carbohydr Polym 76(1):74-85 